\title{
Tackling the COVID-19 Pandemic: Managing the Cause, Spread, and Impact
}

Mohammed Ali Berawi ${ }^{*}$, Nyoman Suwarthaํ, Eny Kusrini², Akhmad Herman Yuwono3, Ruki Harwahyu ${ }^{4}$, Eko Adhi Setiawan ${ }^{4}$, Yandi Andri Yatmo ${ }^{6}$, Paramita Atmodiwirjo ${ }^{6}$, Yuri T. Zagloel ${ }^{5}$, Muhammad Suryanegara ${ }^{4}$, Nandy Putra7 ${ }^{7}$, Muhammad Arif Budiyanto ${ }^{7}$, Yudan Whulanza ${ }^{7}$

${ }^{1}$ Department of Civil Engineering, Faculty of Engineering, Universitas Indonesia, Kampus UI Depok, Depok 16424, Indonesia

${ }^{2}$ Department of Chemical Engineering, Faculty of Engineering, Universitas Indonesia, Kampus UI Depok, Depok 16424, Indonesia

${ }^{3}$ Department of Metallurgical and Material Engineering, Faculty of Engineering, Universitas Indonesia, Kampus UI Depok, Depok 16424, Indonesia

${ }^{4}$ Department of Electrical Engineering, Faculty of Engineering, Universitas Indonesia, Kampus UI Depok, Depok 16424, Indonesia

${ }^{5}$ Department of Industrial Engineering, Faculty of Engineering, Universitas Indonesia, Kampus UI Depok, Depok 16424, Indonesia

${ }^{6}$ Department of Architecture, Faculty of Engineering, Universitas Indonesia, Kampus UI Depok, Depok 16424, Indonesia

${ }^{7}$ Department of Mechanical Engineering, Faculty of Engineering, Universitas Indonesia, Kampus UI Depok, Depok 16424, Indonesia

The outbreak of SARS-CoV-2 or COVID-19 is attacking societies in all regions. The speed and scale of the outbreak have been accelerating fatalities and causing social and economic disruption. We need coordinated and comprehensive actions on the national and international level in creating a sense of shared responsibility and human solidarity to suppress the spread of the virus, empower resilience in society, and address the virus' socio-economic impact. Increasing the healthcare capacity for testing and tracing, implementing quarantine and physical distancing measures, restricting movement, and prioritizing the most vulnerable groups - the elderly and/or chronically sick patients - should be treated as ways to minimize the spread and impact of the virus. Furthermore, the social and economic dimensions of this crisis must be managed to enhance the resilience of societies and countries.

There have been catastrophic losses due to this pandemic, leading to fatalities and bringing social and economic instability to many urban areas. The approaches to tackling this virus must be well-planned. Protecting society from this pandemic is everybody's business. Governments, the private sector, academics, and professionals, as well as every citizen, need to be engaged and play their role in building a resilient society in terms of health, economic, and social resilience. Citizen empowerment is crucial in mitigating the impacts of the pandemic, including the ability to adapt to shock, panic, and stress and to quickly respond to an unstable environment. 


\section{Technology's role in the pandemic}

Measuring vulnerability and its impact on the economy, on the death rates, on society in general, etc. is necessary for pandemic management strategies to be developed and implemented, including appropriate preparedness and effective responses. Technology needs to be employed to assist us in tackling the pandemic by producing a suitable strategy for monitoring, treating, mitigating, and recovering from the pandemic's impact. To anticipate the impact, a comprehensive plan is required for increasing the capacity for disruptions and surges in demand, especially for basic needs such as health and medicine, food, water, and energy.

The pandemic has been pushing lot of researchers to learn more about the behavior of this strain of virus family known for their crown-like shape. The search for the most suitable vaccines is racing ahead, given the number of mortalities all over the world. Since the viruses attach to the substrate, investigations in the field of materials that can repel them is important. In this sense, the use of nanostructure materials is thought to be a promising solution due to their vast areas that can effectively interact with and kill the virus. Such applications of these useful nanomaterials can be in the form of antimicrobial coatings, drug delivery systems, and biosensors, and they can also be used for environmental purposes. Furthermore, the pandemic creates an increasing demand for chemicals and supporting materials such as hand sanitizer, disinfectant, and face masks to prevent the spread of COVID-19 and an increased need for healthy drinking water and clean handwashing facilities.

Modern technology makes a lot of research approaches and endeavors into this matter possible. Several simulators and a lot of modelling software enable researchers to quickly represent the properties of COVID-19 and predict its behavior, both on the microscale (e.g., microbiology, medical, and pharmaceutical fields) and the macro-scale (e.g., COVID-19 transmission and spread). Gathering related data during the COVID-19 outbreak, such as using mobile devices, temperature, and other situation-aware IoT sensors to track location, allows data scientists and artificial intelligence (AI) to conduct big data analysis, where researchers can use many tools to obtain valuable insights, make predictions and personalized suggestions, plan and evaluate strategies (e.g., how to manage the supply chain during physical distancing), and save more lives. The advancement of DIY small electronics and robotics also produces several prototypes of useful tools such as ventilators, which have been vital for helping COVID-19 patients and which are in high demand in many healthcare facilities. The use of additive manufacturing and 3D printing is also playing an important role in addressing the part shortages and supply chain challenges.

In terms of urban development, the current situation in the COVID-19 pandemic suggests the need to rethink the role of resilience knowledge and practices to contribute strategically by ensuring the performance of the built environment to meet the current health-related needs. Research and designs focusing on building material performance and indoor environmental quality become critical to promote architecture that supports hygiene, infection control, and occupants' health and safety. The resiliency of any nation facing this pandemic also depends on the supply chain management (SCM) system of food, medicines, materials, and anything related to life savings and the economy, since SCM manages the flow of information to attain a level of synchronization between responsiveness and cost efficiency. Furthermore, physical distancing measures highlight the fact that the advancement of information technology must continuously improve in order to create a more reliable and robust logistics service. 
Changing how workplaces run and reducing activity in the industrial sectors that have a high energy consumption intensity such as factories, airports, and entertainment venues will lead to much lower energy needs, while in the household sector, medical service locations such as hospitals and health clinics will increase the number and the use of them, the energy demands, etc. Electricity network operators in each country should prepare for fluctuations in power demand and a need to balance the electricity grid and maintain the power system reliability. Many offices and business centers are turning to the internet as a means to work remotely. As many people are now getting familiar with online facilities for work and school, robust broadband, internet, and data center technologies are required to keep everything working together seamlessly even during peak load. In addition, cyber security plays an important role in protecting remote users and their data as well as in quickly mitigating negative, false, or misleading content.

\section{Advancing Technological Performance}

This edition, we are pleased to present twenty selected papers dedicated to advancing technology in terms of strengthening scientific research and technological performance and improvement.

The first paper, written by I. Plazonić, V. Džimbeg-Malčić, I. Bates, and Ž. BarbarićMikočević, investigates the effects of photo-oxidation on the properties of hemp office papers. The authors argue that the values of the tensile index, Bekk smoothness, and the $\mathrm{pH}$ of paper extracts decreased, while the values of elongation at break, the tear index, and Bendtsen roughness increased due to accelerated aging.

The next paper, written by H. Ibrahim, A.S. Silitonga, Rahmawaty, S. Dharma, A.H. Sebayang, Khairil, Sumartono, J. Sutrisno, and A. Razak, examines the use of ultrasound in transesterification to optimize the biodiesel production from rice bran oil. The authors argue that the optimal parameters are a 6:1 ratio of methanol to oil, a 48-minute reaction time, and a $0.5 \%$ wt catalyst.

The third paper, written by A. Darvish, S.R. Eghbali, G. Eghbali, and Y.G. Mahlabani, investigates the effects of a building's glass façade geometry on wind infiltration and heating and cooling energy consumption. The authors argue that a convex geometry reduces the wind pressure in the outer shell and the air exchange rate resulting from the infiltration; thus, heating and cooling energy consumption is reduced.

The fourth paper, written by S. Mau, Yanuar, and A.S. Pamitran, investigates the rheology characteristics and critical velocity of particle-laden flows affected by a threelobed spiral pipe. The authors argue that the low critical velocity value is influenced by the geometry of the spiral pipe, where the tangential velocity generated becomes a trigger for the particle.

The fifth paper, written by L. Bekbayeva, E. Negim, Y. Gulzhakhan, and E. Ganjian, examines the utilization of poly (polyvinyl alcohol -g- 2-ethylhexyl acrylate) as an admixture for mortar. The authors argue that the formation of a polymer film filled the pores and reduced water absorption, increasing the mortar's strength.

The next paper, written by S. Kartohardjono, M.S. Rizky, E.F. Karamah and W-J. Lau, investigates the effect of fiber numbers in hollow fiber membrane modules for NOx absorption. The authors argue that that the absorption efficiency increased, but the mass transfer coefficient and flux decreased as the number of fibers in the membrane module increased at the same feed gas flow rate.

The seventh paper, written by L. Sule, A.A. Mochtar, and O. Sutresman, examines the performance of an undershot water wheel with a bowl-shaped blades model. The authors argue that water turbines with bowl-shaped blades can be used in small-scale electric 
generators with the highest efficiency $(\eta=74.22 \%)$ in the six-blade turbine with a discharge of $0.01228 \mathrm{~m}^{3} / \mathrm{s}$.

The eighth paper, written by A.A. Arrieta, Y.E. Núñez, and J.M. Mendoza, presents a mini electronic tongue that used a polymeric sensor array made from polypyrrole to discriminate between coffee samples of different geographical origin. The authors argue that the device is able to distinguish chemistry and gustatory properties: $\mathrm{NaCl}$ (saltiness), sucrose (sweetness), caffeine (bitterness), citric acid (sourness), and vanillin (bitterness).

The next paper, written by Suprapto, E.O. Ningrum, T. Gotoh, N. Humaidah, R. Febryanita, and M.S. Firdaus, investigates the effect of the synthesis condition on the ability of the swelling, adsorption, and desorption of zwitterionic sulfobetaine-based gel. The authors argue that the swelling degree and adsorption values increased as the temperature decreased in the gel with NIPAM:DMAAPS ratios of 9:1 and 8:2.

The tenth paper, written by E. Yustanti, A. Trenggono, and A. Manaf, investigates the physical and microwave absorption characteristics of high-powered ultrasonically irradiated crystalline particles. The authors argue that the highest absorption value achieved by the nanostructures is $19.75 \mathrm{~dB}$ at $13.6 \mathrm{GHz}$, and the intensity of the incoming electromagnetic waves is reduced by approximately $90 \%$.

The eleventh paper, written by R. Setyaningrum, Subagyo, and A.R. Wijaya, examines product success factors for the Indonesian market using design of experiment. The authors argue that six standardized success factors affected the success of various products: price, product performance, brand, aesthetic design, services, and marketing.

The next paper, written by A. Mubarak and I. Rahman, presents a comparative analysis of carbon emissions from the transportation and logistics of the consumer goods industry in Southeast Asia. The authors argue that the production numbers, the distance traveled, the ratio of road and sea transportation, and the transshipment centers are affecting the output of $\mathrm{CO}_{2}$ emissions.

The thirteenth paper, written by R. Zuraida and B.S. Abbas, determines the factors influencing fatigue related to intercity bus drivers' accidents. The authors argue that the most relevant factors related to the fatigue of intercity bus drivers are the need for recovery and emotional intelligence variables.

The fourteenth paper, written by A.O. Moeis, F. Desriani, A.R. Destyanto, T.Y. Zagloel, A. Hidayatno, and Aziiz Sutrisno, investigates the dynamics and sustainability of port clusters. The authors argue that a free trade policy and shore power system program policies increase the sustainability of a port cluster by optimizing economic activities while managing emission levels.

The next paper, written by B. Poerwadi, C.W. Kartikowati, R. Oktavian, and O. Novaresa, evaluates the hydrophobicity of silica nanoparticle composite membrane manufacture for oil-water emulsion separation. The authors argue that the optimal ratio of water to waterglass in the solution occurred at 19:1, which provided the best hydrophobicity.

The sixteenth paper, written by F. Zukhruf, R.B. Frazila, and W. Widhiarso, investigates the performance of swarm-based algorithms in the design of container terminal facilities. The authors argue that an increase in the number of trucks and gantry cranes improves container terminal performance.

The next paper, written by A. Dhini, A. Faqih, B. Kusumoputro, I. Surjandari, and A. Kusiak, proposes data-driven approaches for a fault diagnosis system based on dissolved gas analysis (DGA) data using a support vector machine (SVM). The authors argue that the model has a high accuracy for all stages in the proposed multistage fault diagnosis system.

The eighteenth paper, written by R. Anggarani, L. Aisyah, C.S. Wibowo, Y.S. Nugroho, and I.M.K. Dhiputra, investigates the possibility of substituting liquid petroleum gas (LPG) 
with dimethyl ether (DME). The authors argue that DME has a 67.8\% lower working region and a 79.7\% lower burning load than LPG.

The nineteenth paper, written by R. Hidayat and A. Winursito, presents an improvement in the accuracy of an isolated word recognition system by utilizing the number of syllables. The authors argue that the method is able to increase the conventional recognition system accuracy by $4 \%$ and improve computing time.

The last paper, written by N.S. Indrasti, A. Ismayana, A. Maddu, and S.S. Utomo, presents the synthesis of nano-silica from boiler ash in the sugar cane industry using the precipitation method. The authors argue that the precipitation $\mathrm{pH}$ and aging time affected the characteristics of the nano-silica, including the particle size, polydispersity index (PDI), crystal size, crystallinity degree, and crystal phase.

We hope that this edition of IJTech conveys some new insights into the way we conduct our research. We are pleased to accept and respond to any comment or enquiry you may have on the direction and content of IJTech, and we invite you to join us in this venture by sending your work for consideration.

With warmest regards from Jakarta,

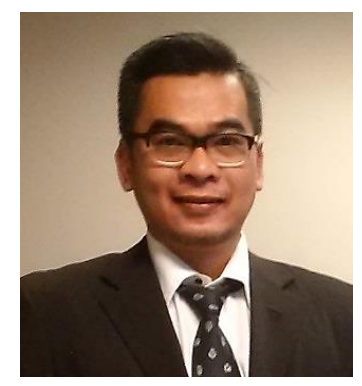

Dr. Mohammed Ali Berawi Editor in Chief

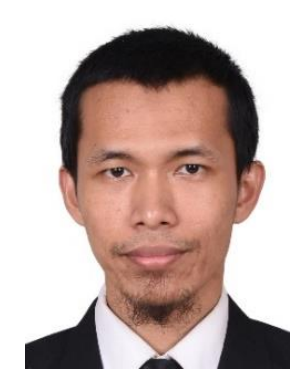

Dr. Ruki Harwahyu Editorial Board Member

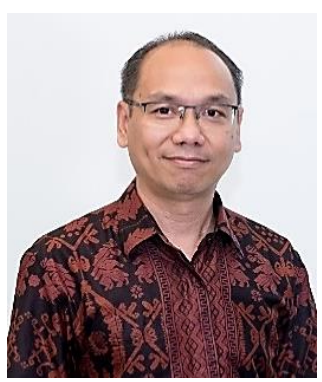

Dr. Nyoman Suwartha Managing Editor

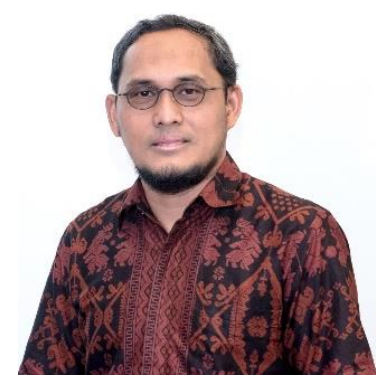

Dr. Eko Adhi Setiawan Editorial Board Member

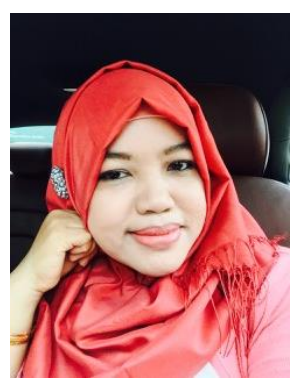

Dr. Eny Kusrini Editorial Board Member

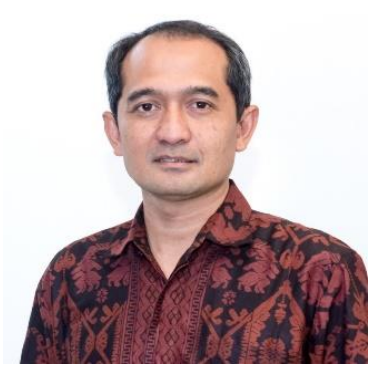

Prof. Yandi Andri Yatmo Editorial Board Member

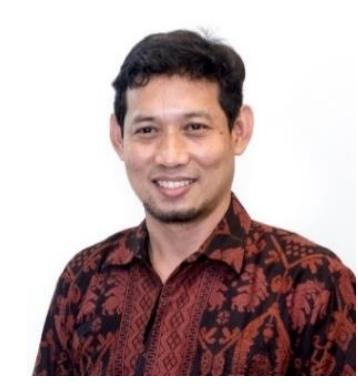

Prof. Akhmad Herman Yuwono Editorial Board Member

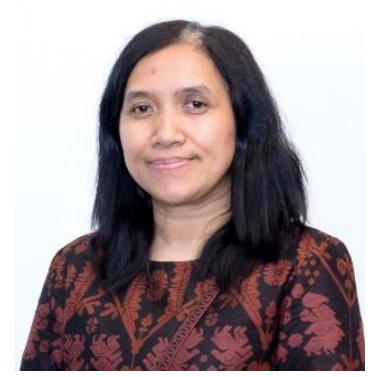

Prof. Paramita Atmodiwirjo Editorial Board Member 


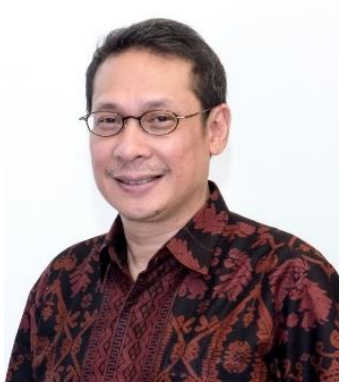

Prof. Yuri T. Zagloel Editorial Board Member

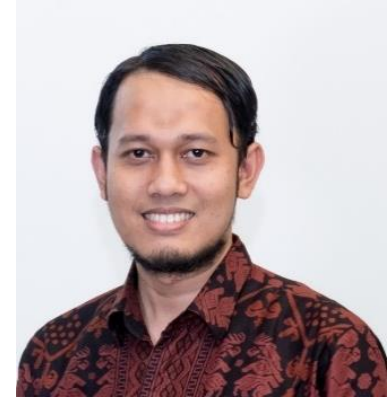

Dr. Muhammad Suryanegara Editorial Board Member

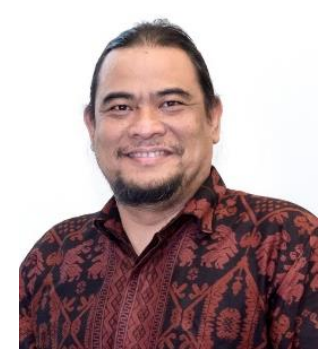

Prof. Nandy Putra Editorial Board Member

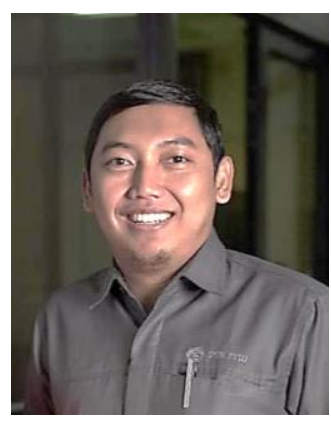

Dr. Muhammad Arif Budiyanto Editorial Board Member

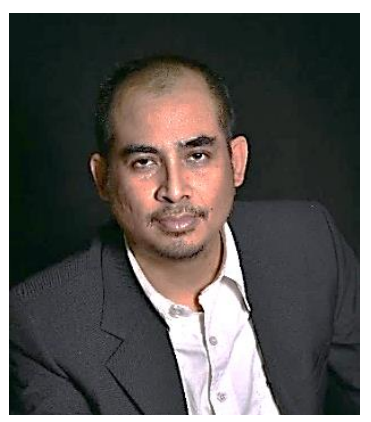

Dr. Yudan Whulanza Editorial Board Member 